\title{
Monika SIEDENTOPF, Parachutées en terre ennemie
}

Traduit de l'allemand par Amélie de Maupeaou, Paris, Perrin, 2008, 266 pages

\section{Marie-Jo Bonnet}

\section{(QpenEdition}

\section{Journals}

\section{Édition électronique}

URL : http://journals.openedition.org/clio/9524

DOI : 10.4000/clio.9524

ISSN : 1777-5299

Éditeur

Belin

\section{Édition imprimée}

Date de publication : 15 décembre 2009

Pagination : 287-288

ISSN : $1252-7017$

\section{Référence électronique}

Marie-Jo Bonnet, « Monika siedentopf, Parachutées en terre ennemie », Clio. Histoire, femmes et sociétés [En ligne], 30 | 2009, mis en ligne le 23 août 2013, consulté le 21 septembre 2020. URL : http:// journals.openedition.org/clio/9524; DOI : https://doi.org/10.4000/clio.9524

Ce document a été généré automatiquement le 21 septembre 2020.

Tous droits réservés 


\title{
Monika SIEDENTOPF, Parachutées en terre ennemie
}

Traduit de l'allemand par Amélie de Maupeaou, Paris, Perrin, 2008, 266 pages

\author{
Marie-Jo Bonnet
}

\section{RÉFÉRENCE}

Monika SIEDENTOPF, Parachutées en terre ennemie, traduit de l'allemand par Amélie de Maupeaou, Paris, Perrin, 2008, 266 pages.

1 Disons le tout de suite, le livre de l'historienne allemande Monika Siedentopf, Parachutées en terre ennemie, et le film Femmes de l'ombre, tiré de ses recherches n'ont pas grand-chose à voir ensemble. Autant le livre ouvre une nouvelle page de l'histoire de la participation des femmes à la Résistance contre l'occupant nazi, autant le film tire les ficelles d'un pseudo-héroïsme féminin qui conforte les mythes au détriment de la réalité historique. Ce qui est un comble quand on découvre la richesse de cette histoire, inconnue en France, et quelque peu iconoclaste puisqu'elle traite de la "guerre subversive " que les services secrets britanniques ont mené en France à travers le SOE (Special Opérations Executive), souvent en rivalité avec les services secrets de la France Libre (BCRA) domiciliés à Londres.

2 Trente-neuf femmes ont appartenu à la section F (France) du SOE et ont été parachutées en France, entre 1942 et 1944, pour accomplir des actes de sabotages ou, le plus souvent, servir d'agent de liaison pour les réseaux mis en place par les Britanniques à partir du terreau existant sur place. La grande supériorité des Britanniques sur les Français, était de disposer d'armes, d'argent, d'appareils radios, d'équipes réceptrices en Angleterre et d'avions susceptibles de traverser la Manche pour des largages de containers d'armes indispensables à la résistance intérieure.

3 Yvonne Rudellat, Andrée Borel, Vera Leight, Violette Szabo, Denise Bloch, Noor Inayat Kahn, sans oublier l'américaine Virginia Hall, dont une biographie est sortie 
récemment ${ }^{1}$, ont ainsi apporté une contribution tout à fait essentielle au combat armé, réservé généralement aux hommes, et tellement dangereux que les trois quarts d'entre elles y laissèrent leur vie. On apprend ainsi que celles qui n'ont pas été victimes de leur inexpérience ou des coups de filet de la gestapo et des services de contre espionnage allemands, ont été trahies par le Français Henri Déricourt, qui était un agent triple et dont on découvre les machinations à travers le récit de Monika Siedentopf alimenté à la source des archives anglaises qui constituent d'ailleurs l'origine essentielle de son travail.

4 Voilà une histoire passionnante, très bien documentée, qui nous apporte le point de vue anglais qui manquait aux études sur la résistance en France. Une dernière remarque : est-ce l'inconscient de l'auteur (d'origine allemande) qui s'est manifesté en employant le mot «terre ennemie » pour parler de la France occupée ? On complétera cette lecture par la traduction du livre référence de Michael R.D. Foot, Des Anglais dans la Résistance, Le Service Secret Britannique d'Action, SOE en France, 1940-1944, paru chez Tallandier en 2008.

\section{NOTES}

1. Vincent Nouzille, L'espionne : Virginia Hall, Une Américaine dans la guerre, Fayard, 2007. 